\title{
A prática influenciando a formação e a aprendizagem na Educação Profissional e
}

\section{Tecnológica}

\author{
Practice influencing formation and learning in Professional and Technological Education \\ Práctica que influye en la formación y el aprendizaje en la Educación Tecnológica y Profesional
}

Recebido: 08/05/2021 | Revisado: 16/05/2021 | Aceito: 20/05/2021 | Publicado: 06/06/2021

Temilson Costa

ORCID: https://orcid.org/0000-0002-5667-0148 Instituto Federal de Educação, Ciência e Tecnologia do Ceará, Brasil

E-mail: costatemilson@gmail.com

Samuel Brasileiro Filho

ORCID: https://orcid.org/0000-0002-4074-1212 Instituto Federal de Educação, Ciência e Tecnologia do Ceará, Brasil E-mail: samuelbrasileirofilho@gmail.com

Pedro Bruno Silva Lemos

ORCID: https://orcid.org/0000-0001-7235-9846 Universidade da Integração Internacional da Lusofonia Afro-Brasileira, Brasil E-mail: pedrobruno_lemos@yahoo.com.br

\begin{abstract}
Resumo
A relação entre a teoria e a prática caracteriza e define ações pedagógicas que possibilitam melhor compreender o processo de ensino e aprendizagem. Por meio deste trabalho, tentou-se encontrar respostas que estabeleçam análises reflexivas sobre os fatores que orientam o entendimento docente sobre a ação pedagógica e os benefícios que as atividades práticas desenvolvem na aprendizagem. Isto posto, abordou-se uma proposta de elucubração do viés acadêmico, intencionando-se investigar as atividades práticas desenvolvidas na Educação Profissional e Tecnológica. Ademais, articulou-se a teoria e a prática no processo de ensino e de aprendizagem, de forma a mobilizar os saberes críticos necessários à formação pessoal e profissional. Nesse contexto, buscou-se refletir se as atividades práticas, na Educação Profissional e Tecnológica, protagonizam uma prática fundamentada na teoria. Além disso, verificou-se a importância da teoria se relacionando com a prática no processo de ensino e de aprendizagem e identificou-se as variáveis e os condicionantes que orientam o fazer pedagógico dos docentes na aplicação de atividades práticas. $\mathrm{O}$ presente artigo é parte dos resultados de nossa pesquisa de mestrado e fundamenta-se numa abordagem metodológica baseada numa pesquisa bibliográfica, apoiada por uma investigação qualitativa, que explora e reflete sobre o fazer pedagógico na Educação Profissional e Tecnológica. Nessa esteira, sintetizam-se algumas reflexões sobre os aspectos analisados dessa temática, de acordo com o pensamento de autores, como Barato (2002, 2008, e 2011), Saviani (2007), Gamboa (2010), Pimenta (2009), Silva (2013), Guimarães (2014), dentre outros, e apresentam-se algumas ações de atividades práticas realizadas no IFCE Campus Baturité. Como resultado, este trabalho contribui para a implementação de aulas dinâmicas, que possibilitam, além dos debates e discussões em sala de aula, realizar atividades que contextualizem a aprendizagem, tanto na academia, como também, no mercado de trabalho. Desse modo, concluiu-se que as experiências práticas realizadas em diversos cursos do Instituto Federal de Educação, Ciência e Tecnologia do Estado do Ceará, Campus Baturité, fundamentam o trabalho e confirmam a importância da relação teoria e prática no processo de ensino e de aprendizagem.
\end{abstract}

Palavras-chave: Educação profissional e tecnológica; Teoria e prática; Práxis; Aprendizagem; Ação pedagógica.

\begin{abstract}
The relationship between theory and practice characterizes and defines pedagogical actions that make it possible to better understand the teaching and learning process. Through this work, we tried to find answers that establish reflective analyzes about the factors that guide the teaching understanding about pedagogical action and the benefits that practical activities develop in learning. That said, a proposal was made to clarify the academic bias, with the intention of investigating the practical activities developed in Professional and Technological Education. In addition, theory and practice were articulated in the teaching and learning process, in order to mobilize the critical knowledge necessary for personal and professional training. In this context, we sought to reflect on whether practical activities, in Professional and Technological Education, play a practice based on theory. In addition, the importance of theory in relation to practice in the teaching and learning process was verified and the variables and conditions that guide the pedagogical practice of teachers in the application of practical activities were identified. This article is part of the results of our master's research and is based on a methodological approach based on a bibliographic research, supported by a qualitative investigation, which explores and reflects on the pedagogical practice in Professional and Technological Education. In this way, some reflections on the analyzed aspects of this theme are synthesized,
\end{abstract}


according to the thinking of authors, such as Barato (2002, 2008, and 2011), Saviani (2007), Gamboa (2010), Pimenta (2009), Silva (2013), Guimarães (2014), among others, and some practical activities carried out at IFCE Campus Baturité are presented. As a result, this work contributes to the implementation of dynamic classes, which make it possible, in addition to the debates and discussions in the classroom, to carry out activities that contextualize learning, both in academia and in the labor market. Thus, it was concluded that the practical experiences carried out in several courses of the Federal Institute of Education, Science and Technology of the State of Ceará, Campus Baturité, substantiate the work and confirm the importance of the relationship between theory and practice in the teaching and learning process.

Keywords: Professional and technological education; Theory and practice; Praxis; Learning; Pedagogical action.

\section{Resumen}

La relación entre teoría y práctica caracteriza y define acciones pedagógicas que permiten comprender mejor el proceso de enseñanza y aprendizaje. A través de este trabajo, buscamos encontrar respuestas que establezcan análisis reflexivos sobre los factores que orientan la comprensión docente sobre la acción pedagógica y los beneficios que las actividades prácticas desarrollan en el aprendizaje. Dicho esto, se hizo una propuesta para esclarecer el sesgo académico, con la intención de investigar las actividades prácticas desarrolladas en Educación Profesional y Tecnológica. Además, la teoría y la práctica se articularon en el proceso de enseñanza y aprendizaje, con el fin de movilizar los conocimientos críticos necesarios para la formación personal y profesional. En este contexto, se buscó reflexionar sobre si las actividades prácticas, en Educación Profesional y Tecnológica, juegan una práctica basada en la teoría. Además, se verificó la importancia de la teoría en relación con la práctica en el proceso de enseñanza y aprendizaje y se identificaron las variables y condiciones que orientan la práctica pedagógica de los docentes en la aplicación de las actividades prácticas. Este artículo es parte de los resultados de nuestra investigación de maestría y se basa en un enfoque metodológico basado en una investigación bibliográfica, sustentado en una investigación cualitativa, que explora y reflexiona sobre la práctica pedagógica en la Educación Profesional y Tecnológica. De esta manera, se sintetizan algunas reflexiones sobre los aspectos analizados de este tema, según el pensamiento de autores, como Barato (2002, 2008 y 2011), Saviani (2007), Gamboa (2010), Pimenta (2009), Se presentan Silva (2013), Guimarães (2014), entre otros, y algunas actividades prácticas realizadas en IFCE Campus Baturité. Como resultado, este trabajo contribuye a la implementación de clases dinámicas, que posibilitan, además de los debates y discusiones en el aula, realizar actividades que contextualicen el aprendizaje, tanto en la academia como en el mercado laboral. Así, se concluyó que las experiencias prácticas realizadas en varios cursos del Instituto Federal de Educación, Ciencia y Tecnología del Estado de Ceará, Campus Baturité, corroboran el trabajo y confirman la importancia de la relación entre teoría y práctica en la docencia. y proceso de aprendizaje.

Palabras clave: Educación profesional y tecnológica; Teoría y práctica; Práctica; Aprendiendo; Acción pedagógica.

\section{Introdução}

Compreender a importância da teoria influenciando atividades práticas no processo de ensino e de aprendizagem e buscar parâmetros que orientem o desenvolvimento do fazer docente estimulando didáticas pedagógicas na Educação Profissional e Tecnológica são os aspectos abordados neste artigo. Sendo assim, articularam-se reflexões que proporcionem posicionamentos político-pedagógicos, nos quais a ação educativa, fundada na relação entre a teoria e a prática, seja elemento básico na formação humana intencionada e direcionada aos discentes da Educação Profissional e Tecnológica.

Portanto, pretende-se, com este artigo, encontrar respostas que visem a estabelecer padrões e reflexões, que sirvam para analisar os fatores da relação existente entre atividades práticas e teorias educativas, orientadas pelas seguintes questões investigativas: Como a teoria orienta o entendimento docente e proporciona sentido às atividades práticas no processo de ensino e de aprendizagem? Como as atividades práticas desenvolvem a melhoria da aprendizagem, ocasionando ampliação de competências profissionais nos discentes?

O presente estudo baseia-se nos pensamentos de alguns autores referenciais para esta temática (Barato, 2002, 2008, 2011; Saviani, 2007; Gamboa, 2010; Pimenta, 2009; Silva, 2013; Guimarães, 2014) que analisam os problemas existentes no processo formativo e apresentam evidências sobre o entendimento da relação teoria e prática, fundamentada, principalmente, no pensamento de Moran (2013), quando aborda que o processo de aprendizagem é "melhor quando vivenciamos, experimentamos e sentimos. Aprendemos quando relacionamos, estabelecemos vínculos, laços, entre o que está solto, caótico, disperso, integrando-o em um novo contexto, dando-lhe significado, encontrando um novo sentido" (Moran, 2013, p. 23). Discute-se, neste estudo, a relação entre a teoria e a prática, caracterizando implicações que permitam situar as diversidades e 
os fundamentos, que mobilizem a ação pedagógica. Desse modo, analisa-se a adequação de atividades que conciliam o detalhamento de saberes especificados nas diferentes áreas do saber, do ensino e da aprendizagem num trajeto investigativo da teoria e da prática no campo da Educação Profissional e Tecnológica.

Como viés metodológico, o presente estudo foi alicerçado numa pesquisa bibliográfica sobre essa temática de forma a destacar o pensamento de autores que referenciam a teoria fundamentando a prática e vice-versa. Predominantemente, considerando-se as intenções investigativas deste objeto de pesquisa, trata-se de um trabalho de cunho qualitativo apoiado em instrumentos de investigação que possibilitam refletir sobre o fazer pedagógico na Educação Profissional e Tecnológica e suas especificidades relativas à articulação necessária entre a teoria e a prática, entre o saber e o fazer.

Assim sendo, este estudo intenciona investigar se as atividades práticas desenvolvidas na Educação Profissional e Tecnológica articulam aprendizagem, desenvolvendo saberes críticos necessários à formação pessoal e profissional dos indivíduos. Em adicional, busca-se compreender a importância que a teoria assume no desenvolvimento de atividades práticas que influenciam o processo de ensino e de aprendizagem. Também se reflete a respeito das variáveis e dos condicionantes chave que orientam o fazer pedagógico dos docentes na aplicação de atividades práticas.

$\mathrm{O}$ artigo encontra-se estruturado com uma introdução, fundamenta-se teoricamente o trabalho por meio das discussões de diversos autores que debatem a relação existente entre a teoria e a prática na Educação Profissional e Tecnológica. Em seguida, apresentam-se os resultados, a partir de experiências práticas desenvolvidas no IFCE Campus Baturité e encerra-se o estudo abordando as considerações julgadas mais relevantes para a realização deste trabalho.

\section{Metodologia}

No que se refere aos aspectos metodológicos, o presente estudo caracteriza-se como uma proposta de pesquisa descritiva alicerçada em uma abordagem de caráter qualitativo e realizada por meio de pesquisa bibliográfica. A pesquisa descritiva possibilita a identificação e detalhamento do objeto ou fenômeno estudado, mediante a realização de levantamento bibliográfico e/ou de análises interpretativas (Gil, 2008; Nunes, Nascimento, \& Alencar, 2016). Sendo assim, buscou-se realizar uma observação objetiva e minuciosa no contexto que caracteriza a realização de atividades práticas na EPT (Gil, 2008; Nunes, Nascimento, \& Alencar, 2016).

Em adicional, a abordagem de caráter qualitativo se caracteriza por não ser traduzida em números, tornando-se possível verificar a relação entre o objeto de estudo e o pesquisador, favorecendo interpretações de uma análise indutiva (Minayo, 2016). Desse modo, a escolha pela abordagem qualitativa possibilitou o aprofundamento da investigação a partir do contato direto com a situação estudada, assim como proporcionou a análise dos aspectos subjetivos que condicionam as experiências e práticas de ensino descritas nesse estudo (Gil, 2008; Minayo, 2016).

Salienta-se, por fim, que a pesquisa bibliográfica é caracterizada pela análise de materiais e trabalhos que passaram por tratamento analítico durante a elaboração (Gil, 2008). Além disso, a pesquisa bibliográfica é uma etapa do estudo que objetiva o fornecimento de subsídios teóricos e conceituais para o referencial teórico e para a posterior análise dos dados (Gil, 2008; Minayo, 2016). Isto posto, destaca-se que a pesquisa bibliográfica, em artigos e livros que discutissem a relação entre a teoria e a prática no fazer pedagógico específico da Educação Profissional e Tecnológica, fundamentou a análise crítica deste estudo, possibilitando abordar experiências práticas desenvolvidas pelo autor principal desta pesquisa, quando apresenta atividades práticas desenvolvidas no IFCE Campus Baturité.

As atividades e experiências práticas apresentadas neste trabalho, seguiram os critérios e normas utilizadas na Educação Profissional e Tecnológica, principalmente quando se planejou aulas de campo ou atividades práticas. Para cada aula de campo ou atividade prática, o docente responsável elaborou um planejamento prévio e, em seguida, encaminhou a proposta 
para análise e aprovação pelo setor pedagógico. Após aprovação institucional, o docente responsável realizou os procedimentos necessários à execução de aula de campo ou atividade prática planejada.

As propostas de aulas de campo ou atividades práticas possibilitaram, destarte, aos alunos conhecerem in loco equipamentos, empreendimentos e pessoas que estão relacionadas à sua formação profissional (Silva, Marinho, Machado, \& Hoefel, 2019; Silva, \& Fernandes, 2020). Além disso, observa-se que as referidas atividades colocam em prática, de forma interdisciplinar, assuntos relacionados aos conhecimentos teóricos adquiridos em sala de aula, possibilitando entender a relação existente entre a teoria e a prática, diante das disciplinas e a sua formação profissional. Vale salientar que a carga horária de cada atividade variou de acordo com o local a ser visitado ou pessoa convidada para participar de cada ação.

\section{Resultados e discussões}

\subsection{Entendendo a relação teoria e prática}

Silva (2013) comenta que o termo "teorias e práticas" foi proposto por Durkheim (1922), supostamente um dos primeiros autores a considerar a especificidade da construção teórica sobre a prática. Essa proposta afigura-se como algo especial, não apenas pelo reconhecimento de um determinado tipo de saber, mas, também, por ter sido formulada por um positivista. Salienta-se que faz parte dos princípios do positivismo considerar as práticas profissionais como consistindo numa aplicação da teoria à prática, pressuposto que foi posto em causa por diferentes autores, nomeadamente por Ben-Jacob, Goldenfeld, Langer \& Schön, G. (1983), que criticam essa abordagem, como correspondendo a uma perspectiva de "racionalidade técnica".

Para Gamboa (2010), quando refletimos a relação teoria e prática, deve-se entender que a concepção dialética existente entre esses dois conceitos não pode se apresentar como ajuste entre uma e outra, ou seja, adequando a teoria à prática ou vice-versa, mas como o não conflito e tensão entre elas. O mesmo autor ainda aborda que essa inter-relação dialética deverá ser verificada diante de três aspectos, a saber:

O primeiro refere-se à unidade dos termos: não podemos conceber a teoria separada da prática, ou seja, o ser separado do pensamento;

A existência de uma ou outra depende da relação mútua entre elas. É na relação com a prática que se inaugura a existência de uma teoria, não pode existir uma teoria solta, o que existe é sempre a teoria de uma prática; e,

A prática existe, logicamente, como a prática de uma dada teoria. É a própria relação entre elas que possibilita a sua existência. (Gamboa, 2010, p. 07).

Nessa perspectiva, Gamboa (2010) ainda argumenta que a relação existente entre a teoria e a prática se sintetiza no termo práxis, utilizado desde os gregos, na Antiguidade, para designar uma ação propriamente dita. Destaca-se que, baseado nesse pensamento, o termo "prática" é referenciado, neste trabalho, para designar atividades que levam a cabo algo, ou seja, uma ação com fim em si mesma, que não cria ou produz um objeto alheio ao agente ou à sua atividade.

Verifica-se, portanto, que a teoria, viabilizando uma conexão entre o pensar e o fazer, torna a prática um fazer articulado com o aprofundamento teórico. Desse modo, a relação teoria e prática possibilita, ao discente, reinventar o seu pensamento, norteado pelo processo de investigação, pesquisa e ampliação do conhecimento, tendo como base elementos que contextualizam os seus cotidianos nas atividades acadêmicas, pessoais e profissionais.

Buscando maiores subsídios teóricos para fundamentar este artigo, Gamboa (2010) comenta que, para Gramsci, a Filosofia da Práxis, é um projeto prático de construção de um mundo ou nova realidade, ou seja, uma ação transformadora de uma realidade histórica nova, destacando condições determinadas por uma práxis anterior. Gramsci aborda que: "para a filosofia da práxis, o ser não pode ser separado do pensar, o homem da natureza, a atividade da matéria, o sujeito do objeto; faz-se esta separação, cai-se numa das tantas formas de religião ou de abstração sem sentido" (Gramsci, 1989, p. 70). 
Analisando essas reflexões e verificando a importância das atividades práticas na formação dos discentes, e a sua relação baseada nos fundamentos teóricos, compreende-se a educação como uma prática social, fundamentada em uma pedagogia que faz da práxis educacional um elemento que permeia a atividade docente. Porém, questiona-se: Como se dá e que caminhos percorre o docente em sua formação? Quais os aspectos que definem a relação teoria e prática no processo de ensino e de aprendizagem?

Para Pimenta (2009), a atividade docente é intencional, haja vista que os objetos são os processos de ensino e de aprendizagem. A educação torna-se uma prática social, carregada de ideologias, com finalidades "na" e "para" sua transformação. Entende-se a Pedagogia, portanto, enquanto Ciência da Educação, como a ferramenta que "coloca os ‘ingredientes teóricos' necessários ao conhecimento e à intervenção da educação (prática social)” (Pimenta, 2009, p. 93). Nesse contexto, observa-se a atividade docente como práxis, a relação entre teoria e prática com uma didática pedagógica que permite compreender os múltiplos aspectos da sociedade, assim como compreende-se a formação docente como necessária para a ampliação dos conhecimentos e para a geração de transformações em um contexto social.

Masseto (2012) aborda os conceitos da formação pedagógica como reflexões que conscientizam os professores sobre o seu verdadeiro papel docente, observando que, como o exercício de qualquer outra profissão, a docência exige capacitação própria e específica que não se restringe a ter um diploma de bacharel, de mestre ou doutor, ou apenas o exercício de uma profissão. A docência exige, entretanto, competências que possibilitem, ao educador, tornar-se alguém que tem a missão de colaborar eficientemente para que seus alunos apreendam da melhor forma possível (Guimarães, 2014; Masseto, 2012).

Nessa conjuntura, Silva (2013) e Ardoino (1980) comentam que as fundamentações de práticas educativas poderão evoluir no sentido de alguma articulação teórica, mas manter-se-ão sempre "multi-referenciais", tal como acontece com as teorias práticas referenciadas por Durkheim. Silva (2013) cita, como exemplo, a medicina, que é fundamentada em outras ciências, porém, como todas as outras, evolui suscitando novas formas de práticas. Porém, considerando a importância dos valores e das ideologias para o processo de ensino e de aprendizagem, percebe-se a existência de certa dificuldade na transposição e mobilização dos contributos do progresso do conhecimento teórico para a prática.

Observa-se, portanto, o fazer pedagógico influenciando e sendo influenciado por outras ciências, e, nesse sentido, Pires (2019) e Neto (2013) abordam que a epistemologia da prática é configurada pelo ideário pedagógico que influencia, de modo significativo, as práticas de formação de professores e a pesquisa em educação no Brasil, se caracterizando como "reflexão na ação, reflexão sobre a ação e a reflexão sobre a reflexão na ação" (Pires, 2019, p. 1109). Valoriza-se, dessa forma, a experiência e a prática docente, influenciando o processo de reforma, proposta a partir de 1996, com a formação de professores ${ }^{1}$, implicando na necessidade de educar os professores para refletirem sobre a sua própria prática pedagógica. Aprofundando essa análise e baseado no conceito de prática como componente curricular, o Parecer CNE/CP 9/2001 apresenta a seguinte definição:

Uma concepção de prática como componente curricular implica vê-la como uma dimensão do conhecimento, que tanto está presente nos cursos de formação nos momentos em que se trabalha na reflexão sobre a atividade profissional, como durante o estágio nos momentos em que se exercita a atividade profissional (Parecer CNE/CP 9/2001, 2001, p. 22).

Assim, fazendo uma relação entre a teoria e a prática, observa-se que a epistemologia da prática se constitui na conjunção de uma pedagogia que prepara o indivíduo para uma educação que cria bases morais, éticas e intelectuais, para que cada pessoa possa seguir seu ritmo com o pressuposto do conhecimento tácito, tendo como objeto de interseção a experiência

${ }^{1}$ Como exemplo dessa influência cita-se o documento publicado pelo MEC, em 1999, intitulado "Referenciais para formação de professores". 
do indivíduo. Essa experiência, tomada em seus pressupostos, é o "cotidiano/prático" sobre o qual a ação se realiza e produz as bases para a construção do conhecimento, que é mediador na formação do indivíduo, baseado no componente curricular prático. Nessa perspectiva, ao analisar o conceito de componente curricular prático, Real (2012) argumenta que:

A palavra "prática" pode-se encontrar no dicionário Aurélio a seguinte explicação: "ato ou efeito de praticar. Um exercício. Rotina; hábito. Saber provido de experiência. Aplicação da teoria". O mesmo entendimento pode ser aplicado ao termo "componente" que é significado da seguinte maneira: "que, ou quem, ou aquilo que entra na composição de algo". Para o verbete "curricular" o mesmo dicionário Aurélio traz a seguinte inscrição: "as matérias constantes de um curso". Em linhas gerais a expressão "prática como componente curricular" significaria, a partir do entendimento extraído do dicionário, que deve haver a aplicação da teoria nas matérias que compõem o programa de um curso. (Real, 2012, p. 50).

Destarte, é muito importante que, no processo de ensino e de aprendizagem, o docente envolva de todas as formas os discentes nos contextos pedagógicos, realizando, assim, aulas práticas participativas, em que os protagonistas da sala de aula (alunos) possam analisar, experimentar e colocar em prática aquilo que veem na teoria, tornando-se agentes multiplicadores do conhecimento. Sobre isso, Franco e Pimenta (2012) salientam que:

Os saberes teóricos propositivos se articulam aos saberes da prática ao mesmo tempo resignificando-os e sendo, por sua vez, resignificados. Assim, o papel da teoria é oferecer aos professores perspectivas de análise para compreenderem os contextos históricos, sociais, culturais, organizacionais e de si mesmos como profissionais, nos quais se dá sua atividade docente, para neles intervir, transformando-os (Franco, \& Pimenta, 2012, p. 21).

Quando se direciona este estudo para a realidade da atividade docente, destaca-se, como fundamento as experiências vivenciadas em sala de aula pelo autor principal deste artigo, como também, suas experiências em ambientes reais de trabalho. Também se reflete, principalmente, a respeito do exercício da profissão de Guia de Turismo, atividade que permitiu-lhe a reinserção no mercado de trabalho no ano de 1988, após ter sofrido um acidente de moto em 1985 e ter se tornado uma pessoa com deficiência, porém, a partir da realização de um curso Técnico, este teve a oportunidade de entender novos parâmetros sobre o seu espaço no mundo do trabalho.

\subsection{A práxis na prática}

A formação em Turismo, no ano de 1992, não possibilitou, ao autor principal deste trabalho, o desenvolvimento de conceitos que evidenciassem o entendimento de práticas pedagógicas. No entanto, quando surgiu o convite, em 1996, para ministrar aulas nos cursos da área de turismo e hospitalidade, no SENAC RN, as práticas docentes foram alicerçadas nas bases conceituais do curso Bacharel em Turismo, e, principalmente, nas experiências vivenciadas como Guia de Turismo.

Nota-se, portanto, que vários fatores influenciaram e motivaram a prática docente. Desse modo, foram evitadas práticas pedagógicas tradicionais que não privilegiavam o protagonismo do discente. Buscou-se, portanto, na pesquisa e na leitura de projetos curriculares, a base que fundamentou a prática profissional. Além disso, os cursos de "Formação Docente", realizados em diversas instituições, melhoraram, consideravelmente, a ação em sala de aula.

Os cursos profissionalizantes da área de turismo e hospitalidade permitem aos alunos uma maior compreensão sobre a importância do fazer profissional, visto que abordam uma base teórica, porém desenvolvem grande parte da carga horária com vivências práticas e atividades inerentes a cada ocupação. Dentre essas atividades trabalhadas em sala de aula, destaca-se que as práticas profissionais dos cursos de Guia de Turismo, de Garçom, de Cozinheiro, de Recepcionista de Hotel e de Camareira necessitam dialogar diretamente com as demandas e exigências do mercado de trabalho. 
É importante salientar ainda que, para melhor desenvolver as aulas, o docente deve preparar um bom planejamento pedagógico, pois se trata dos aspectos fundamentais que nortearão e possibilitarão ao docente compreender o seu real papel de professor, ou seja, de um profissional conhecedor do mercado, que se transforma em agente multiplicador da informação, e que orientará os melhores caminhos que os alunos podem percorrer em busca dos seus ideais. Nessa perspectiva, a relação entre a teoria e a prática proporcionará aos discentes os conhecimentos técnicos sobre as diversas ocupações trabalhadas nos cursos. Além disso, a articulação entre saberes e práticas também possibilitará a compreensão da complexidade e da diversidade que caracterizam o processo de ensino e de aprendizagem (Barato, 2004, 2008, e 2011).

Destarte, como docente, considera-se indispensável apresentar aos discentes uma boa base teórica que proporcione a compreensão dos aspectos fundamentais que embasarão o desenvolvimento da prática profissional. Isso inclui a abordagem de conceitos, apresentação de vídeos, elaboração de projetos e referenciais bibliográficos, os quais visam melhor desenvolver e dinamizar as aulas, permitindo uma compreensão da base teórica abordada por autores, compactuada aos critérios que favorecem o entendimento do assunto, sobretudo relacionando a teoria com as propostas de uma ação prática.

Analisando as experiências vivenciadas desde agosto/2016, quando o autor principal desse trabalho assumiu a vaga de Professor do Ensino Básico, Técnico e Tecnológico, no Instituto Federal de Educação, Ciência e Tecnologia do Estado do Ceará - IFCE, no Campus Baturité, percebe-se que as ações aplicadas em sala de aula estão em consonância com o Projeto Pedagógico do Curso Tecnologia em Hotelaria, pois favorecem um fazer pedagógico que consiste em um processo de construção e reconstrução da aprendizagem. Ressalta-se, ainda, que as ações aplicadas em sala de aula são baseadas na dialética da intenção da tarefa partilhada, em que todos são sujeitos do conhecer e aprender, visando à construção do conhecimento, partindo da reflexão, do debate e da crítica, numa perspectiva criativa, interdisciplinar e contextualizada.

Esse processo visa colocar o aluno em contato com a teoria e a prática, aprofundando, por meio de atividades que envolvem a criação, a construção e a análise, a base que proporciona formar profissionais com autonomia intelectual e moral, tornando-os aptos para participar e criar, exercendo sua cidadania e contribuindo numa visão de sustentabilidade econômica, social e ambiental. Desse modo, organiza-se situações didáticas para que o aluno busque, por meio do estudo individual ou em equipe, soluções para os problemas que retratam a sua realidade profissional (Barato, 2004, 2008, e 2011).

Adicionalmente, ressalta-se que as atividades práticas e aulas de campo também objetivam tornar o aluno protagonista, assim como estimular o processo de aprendizagem (Silva, Marinho, Machado, \& Hoefel, 2019; Silva, \& Fernandes, 2020). Ademais, percebe-se que, ao serem inseridas no currículo escolar, as atividades práticas e aulas de campo tornam-se instrumentos pedagógicos para a formação acadêmica e profissional. (Borges et al, 2020; Nascimento, Bertini, \& Sousa Rios, 2020).

Dessa forma, emprega-se metodologias que propiciam condições para que o aluno vivencie e desenvolva competências cognitivas (aprender a aprender); produtivas (aprender a fazer); relacionais (aprender a conviver) e pessoais (aprender a ser) (Barato, 2004, e 2008). Essas atividades são realizadas durante os momentos teórico-práticos, utilizando metodologias ativas, por meio de apresentação em multimídia, oficinas, fóruns, discussão e estudos de casos, além de análises de filmes, artigos científicos e situações de resoluções de problemas, permitindo discussão e aprendizagem.

Dentre as várias atividades práticas realizadas, destacam-se, a seguir, algumas julgadas importantes para disponibilizar neste trabalho:

a) Ação Social em Escola do Município de Baturité: atividade interdisciplinar realizada na Escola Municipal Estevão Alves da Rocha, envolvendo as disciplinas "Projeto Social", ministrada pela Prof. ${ }^{a}$ Carolina; e a disciplina "Gestão Ambiental na Hotelaria", ministrada pelo autor principal desse trabalho, de acordo com o que foi debatido na 
teoria em sala de aula, com alunos do Curso Técnico em Hospedagem, do Campus IFCE Baturité, realizada em 26/03/2018, conforme Figuras 1(A e B).

Figuras 1 (A e B): Atividade Prática de Gestão Ambiental em escola municipal.
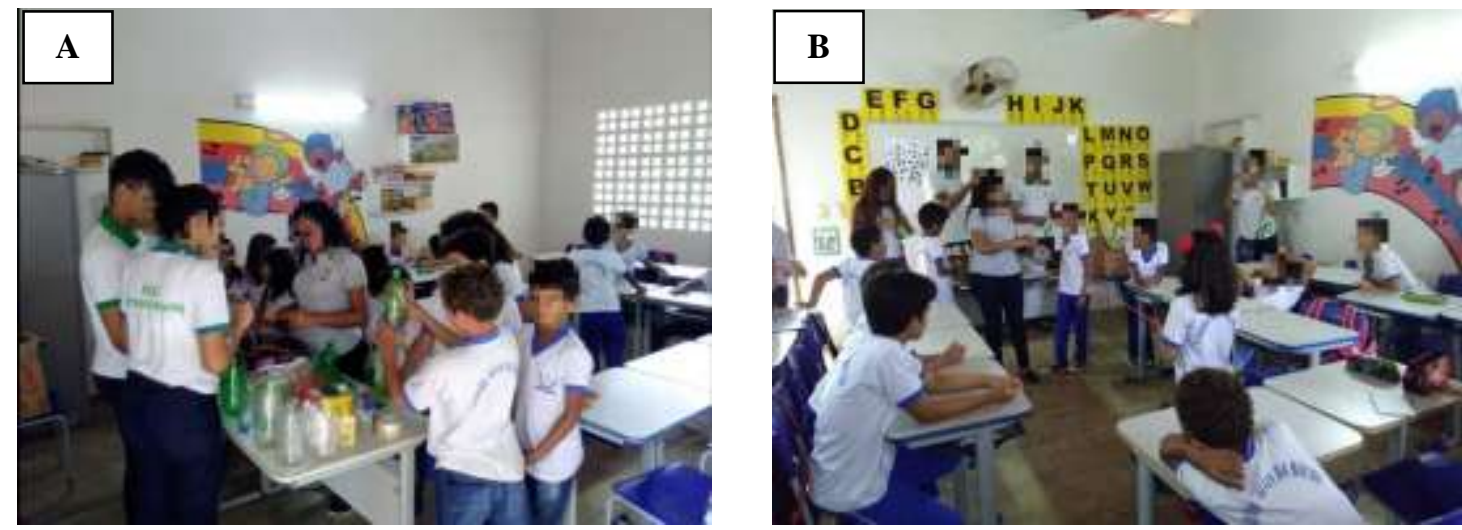

Fonte: Acervo dos autores (2018).

b) Educação Turística e Patrimonial: ação de extensão desenvolvida por bolsistas do curso Tecnologia em Hotelaria do IFCE Campus Baturité, e coordenado pelo autor principal desse trabalho, servindo de atividade prática da disciplina "Introdução ao Estudo do Turismo". Relacionou a teoria e a prática no processo de ensino e de aprendizagem e proporcionou, a mais de 210 alunos do $7^{\circ}$ ano, da Escola Municipal Domingos Sávio, conhecer a história e as potencialidades turísticas e culturais da sua cidade, realizando primeiro encontro na escola, conforme Figuras 2 (C e D), depois, visitas técnicas ao patrimônio histórico e turístico do município de Baturité $\mathrm{CE}$, conforme Figuras 3 (E e F).

Figura 2 (C e D): Atividade de Extensão em escola municipal.
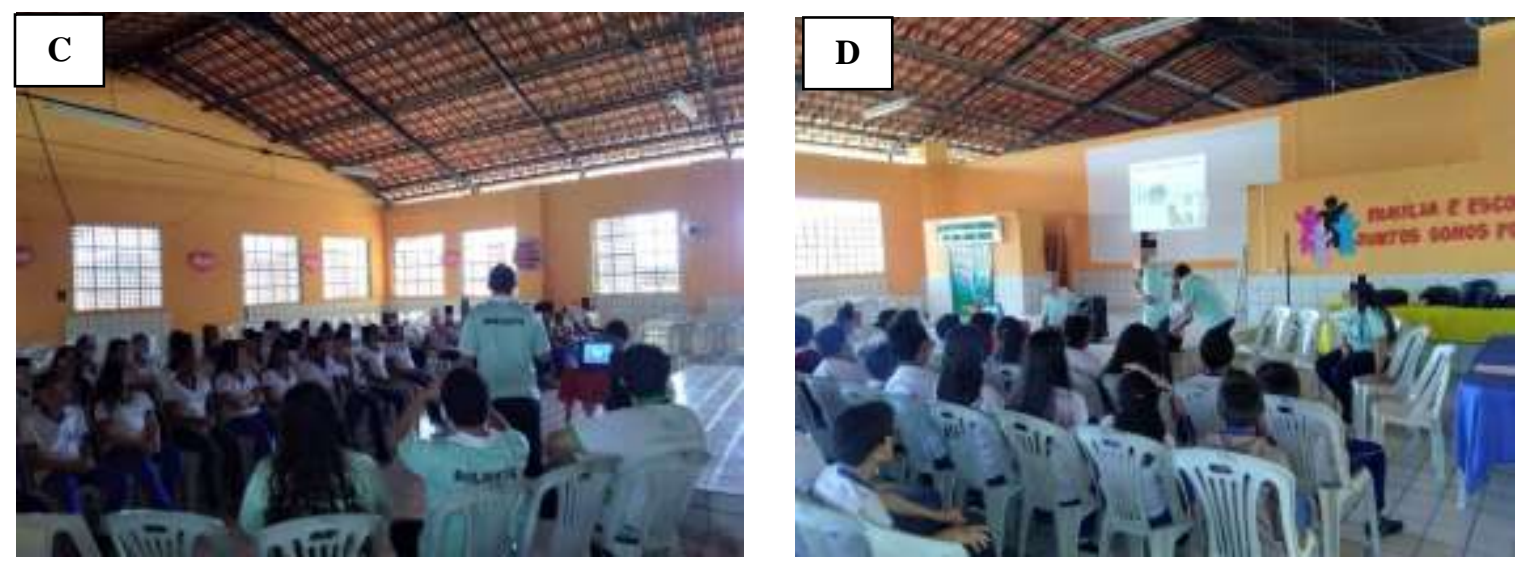

Fonte: Acervo dos autores (2018). 
Figura 3 (E e F): Visita técnica no município de Baturité.
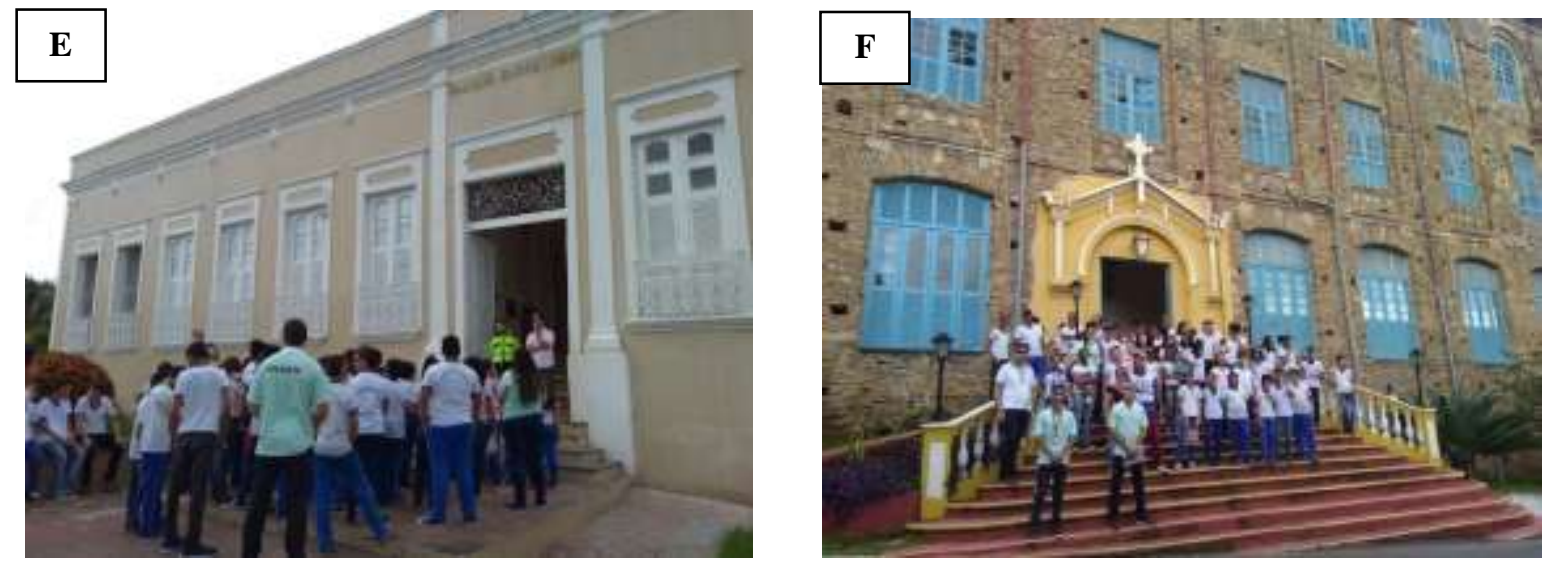

Fonte: Acervo dos autores (2018).

c) Aula prática no curso de Gastronomia do IFCE Baturité: o saber científico se complementando com o saber comum e vice-versa. Aula da disciplina "Gestão Ambiental e Responsabilidade Social", ministrada pelo autor principal desse trabalho, com a participação de Francisco Pereira, jardineiro do Campus Baturité, demonstrando a sua experiência sobre os produtos da horta e demais árvores e todo processo de jardinagem existente no referido Campus do IFCE, conforme Figuras 4 ( $\mathrm{G}$ e H).

Figuras 4: Aula Prática com Francisco (Jardineiro).
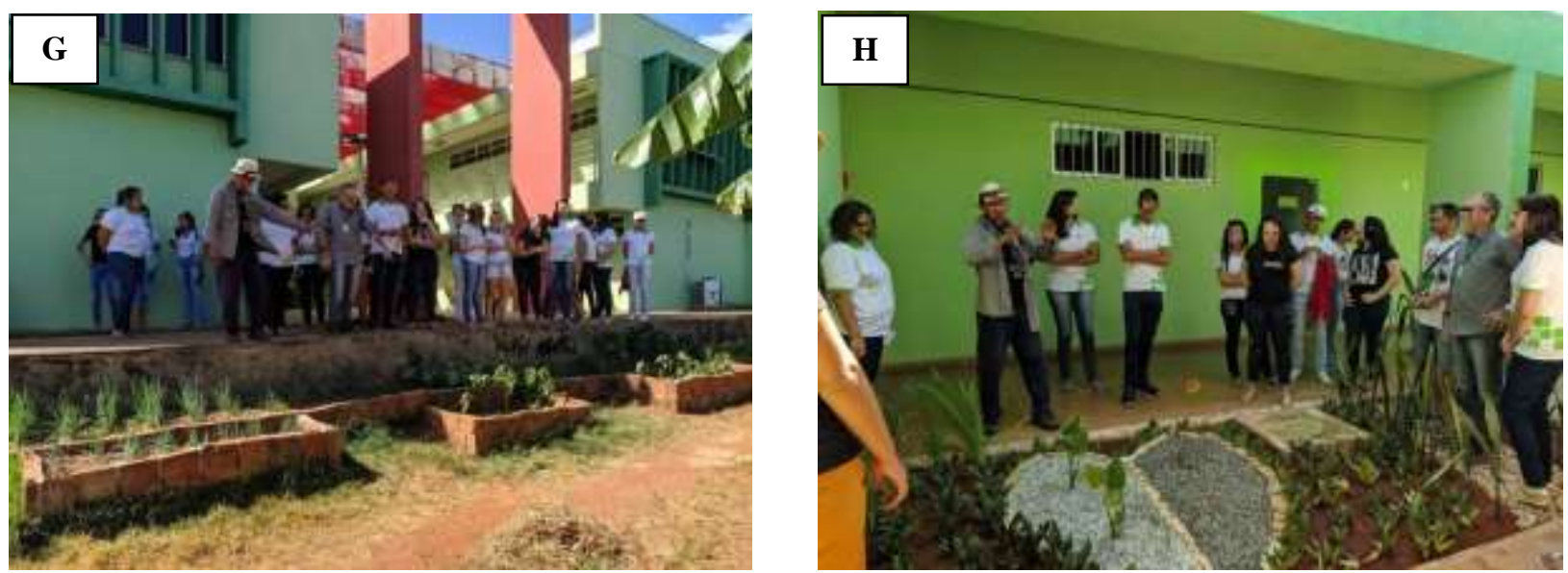

Fonte: Acervo dos autores (2018).

d) Evento de planejamento e organização de eventos: realização do Concurso Miss \& Mister IFCE 2019, planejado, organizado e executado pelos alunos do curso Tecnologia em Hotelaria do IFCE Campus Baturité, como parte da avaliação final da disciplina "Planejamento e Organização de Eventos", ministrada pelo autor principal deste trabalho, conforme Figuras 5 (I e J). 
Figuras 5 (I e J): Concurso Miss \& Mister IFCE 2019.
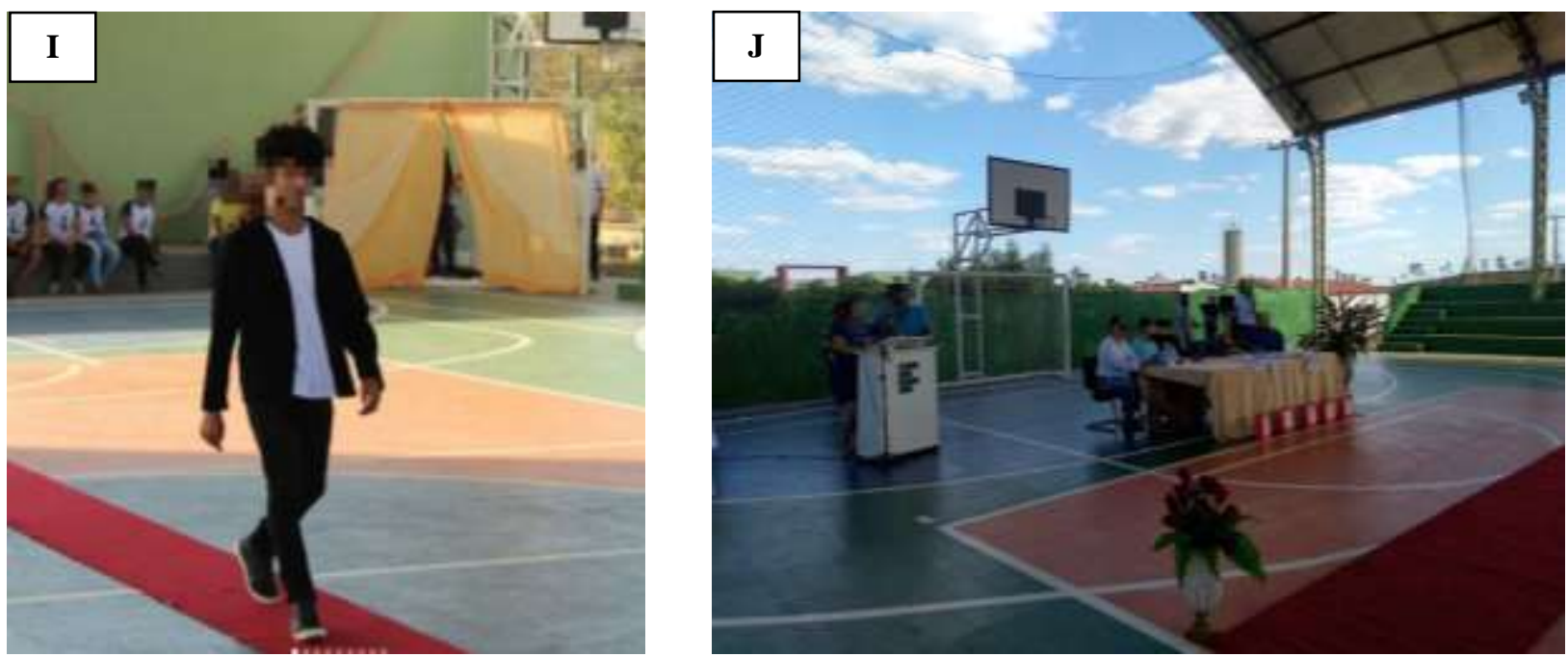

Fonte: Acervo dos autores (2018).

e) Visita técnica ao hotel Vale das Nuvens e ao IFCE Guaramiranga: ações práticas e interdisciplinares na Educação Profissional e Tecnológica oportunizam tirar o aluno de sala de aula e demonstrar as diversas nuances do mercado de trabalho. Planejar uma visita técnica interdisciplinar é possibilitar ao discente compreender que a teoria sempre se relaciona com a prática e vice-versa, proporcionando conhecimentos diferenciados que o acompanharão em sua vida profissional, conforme Figuras 6 (K e L).

Figuras 6 (K e L): Visita Técnica.
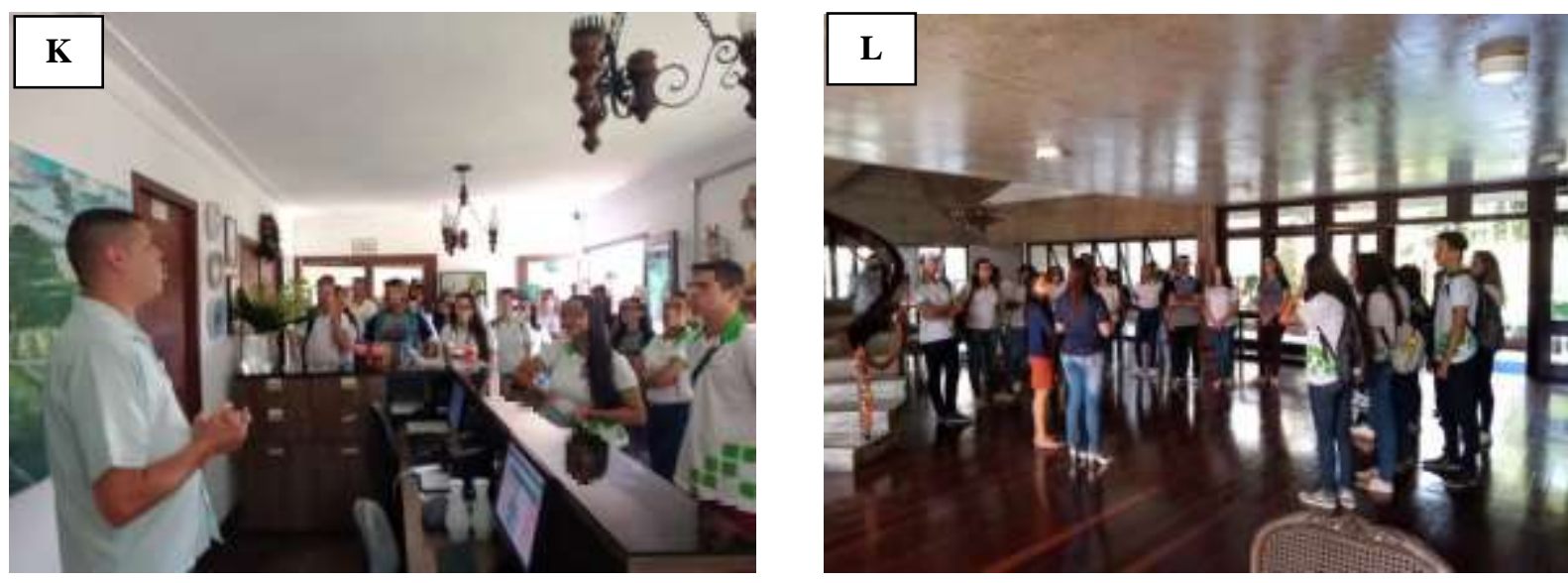

Fonte: Acervo dos autores (2018).

f) Palestra com empresário local: visando a possibilitar uma maior integração entre o mercado e a academia, convidamos um empresário da área de Restaurante para relatar as suas experiências profissionais e aproximar os alunos à realidade do mercado de trabalho, conforme Figuras 7 (M e N). 
Figuras 7 (N e O): Palestra de José Walter.
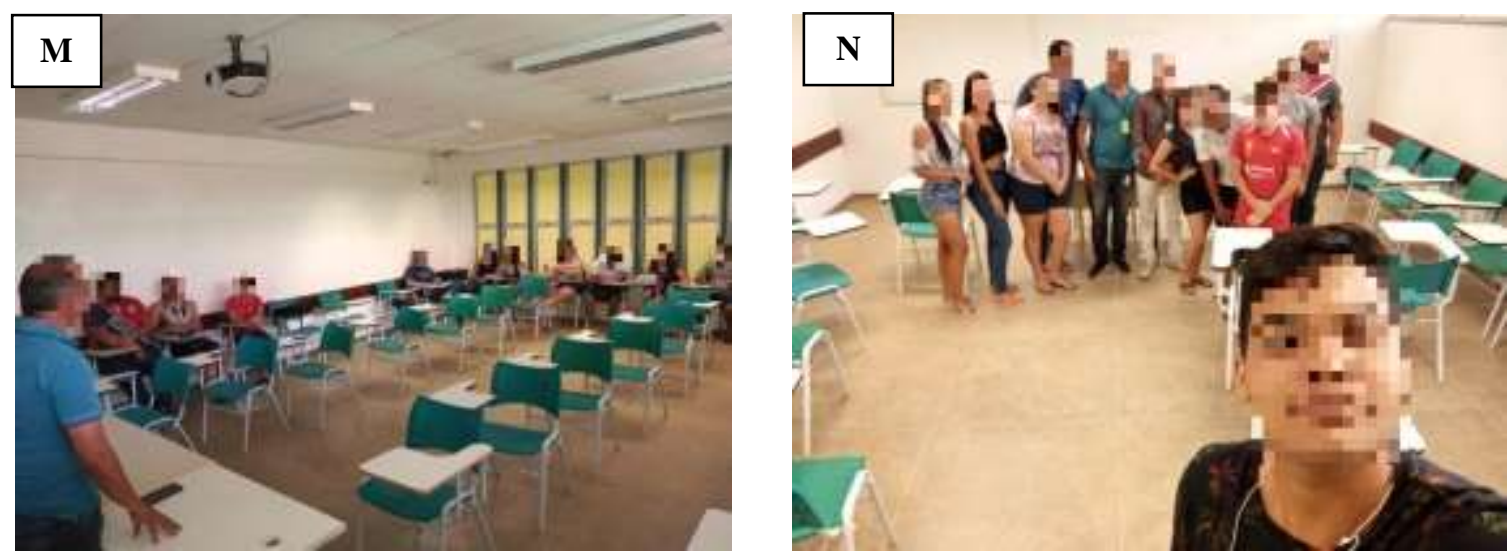

Fonte: Acervo dos autores (2018).

Sabe-se que se pode fazer muito mais pela Educação Profissional e Tecnológica, mesmo existindo dificuldades orçamentárias e de equipamentos, porém, cabe ao docente inovar e realizar ações e atividades que possibilitem aulas mais dinâmicas que, além de proporcionar a relação teoria e prática no processo de ensino e de aprendizagem, evidenciem experiências, conforme apresentadas, servindo como ilustração e referência para este artigo, evidenciando, assim, o pensamento de Saviani (2007), quando aborda que:

a oposição teoria-prática se insinua a oposição verbalismo-ativismo: o que se opõe de modo excludente à teoria não é a prática, mas o ativismo; do mesmo modo, o que se opõe de modo excludente à prática é o verbalismo e não a teoria. Pois o ativismo é a "prática" sem teoria e o verbalismo é a "teoria" sem a prática. Isto é: o verbalismo é o falar por falar, o culto da palavra oca; e o ativismo é a ação pela ação, a prática cega, o agir sem rumo claro, a prática sem objetivo. (Saviani, 2007, p. 109)

Em vista disso, relacionar teoria e prática no processo de ensino e de aprendizagem trata-se de buscar meios que demonstrem uma ação pedagógica transformadora. Essa ação deve permitir entender as reflexões suscitadas neste trabalho, possibilitando também compreender que o papel dos educadores é primordial, nesse processo, para consolidar ações em que o aluno possa desempenhar uma participação proativa, construindo o seu próprio conhecimento, realizado por meio da mediação do professor.

\section{Considerações Finais}

Nas circunstâncias apresentadas neste artigo, verificou-se que a aprendizagem do discente é acompanhada de avaliações que referenciam a teoria e a praticidade das aulas, visando a identificar o nível de entendimento que o aluno adquire na Educação Profissional e Tecnológica, da mesma forma que acompanha o seu rendimento e as dificuldades enfrentadas no decorrer do processo de ensino e de aprendizagem.

Notou-se, porém, que os docentes devem sempre incentivar e abordar, em suas práticas pedagógicas, assuntos que contextualizam a realidade dos discentes, bem como as relações éticas racionais, de gênero e a relevância da sustentabilidade econômica, social e ambiental, que condizem com a realidade da própria sociedade.

Além disso, observou-se que a ação docente vai além das atividades em sala de aula, pois afeta direta e indiretamente o processo de ensino e de aprendizagem. Considerou-se, também, que as atividades complementares proporcionam, aos discentes, experiências que permitem relacionar a teoria e a prática, a partir das atividades de iniciação científica e tecnológica, 
programas de extensão, visitas técnicas, realização de aulas práticas, eventos científicos, além de outras atividades que devem acompanhar o desenvolvimento do curso.

De acordo com as especificidades abordadas neste trabalho, as atividades de formação acadêmica, as aulas práticas realizadas em laboratórios, as visitas técnicas, as participações em eventos na academia e fora dela, os projetos de pesquisa e os de extensão são essenciais para que o aluno possa experimentar diferentes metodologias pedagógicas adequadas ao ensino tecnológico. Sendo assim, destacou-se que o contato do aluno com as atividades práticas deve ser bem planejado, considerando os diferentes níveis de profundidade e complexidade dos conteúdos envolvidos, tipo de atividade, objetivos, competências e habilidades específicas. Isso proporciona, ao aluno, desse modo, um contato com os procedimentos a serem utilizados na aula prática realizada, simultaneamente, por toda a turma e acompanhada pelo professor.

Portanto, a partir das análises e argumentos apresentados a respeito da relação teoria e prática na Educação Profissional e Tecnológica, compreende-se que a implementação de aulas dinâmicas, por meio de atividades práticas, possibilita, além dos debates e discussões em sala em aula, a contextualização da aprendizagem, tanto na academia, como no mercado de trabalho. Verificou-se, também, a importância do equilíbrio entre as práticas pedagógicas e as teorias epistemológicas para que o desenvolvimento de atividades práticas, na Educação Profissional e Tecnológica, proporcione a aprendizagem teórica, assim como o domínio de competências práticas exigidas pelo mercado de trabalho.

Como possibilidade de estudos posteriores, indica-se a necessidade de realizar pesquisas que ampliem as discussões e o debate acadêmico a respeito das formas e condições mais adequadas de direcionar a aprendizagem dos alunos à realidade do mercado, por meio da realização de atividades práticas em cursos técnicos, tecnológicos e/ou licenciaturas.

\section{Referências}

Ardoino, J. (1980). Education and relations: introduction to a multifaceted analysis of educational factors. Gauthier-Villars.

Barato, J. N. (2002). As demandas do saber técnico. In: Barato, J. N (Org.). Escritos sobre tecnologia educacional e educação profissional (pp. 135-151). Editora Senac.

Barato, J. N. (2004). Em busca de uma didática para o saber técnico. Boletim técnico do Senac, 30(3), 47-55.

Barato, J. N. (2008). Conhecimento, trabalho e obra: uma proposta metodológica para a Educação Profissional. Boletim Técnico do Senac, 34(3), 4-15.

Barato, J. N. (2011). Saber do trabalho, aprendizagem situada e ensino técnico. Boletim Técnico do Senac, 37(3), 19-29.

Ben-Jacob, E., Goldenfeld, N., Langer, J. S., \& Schön, G. (1983). Dynamics of interfacial pattern formation. Physical Review Letters, 51(21).

Borges, I. M. S., Almeida, R. L., Lima, C. A. O., Fernandes, A. C. G., Gomes, R. M., Silva Araújo, W, \& Silva, E. C. (2020). Contribuições do trabalho de campo para aulas de geografia no ensino fundamental. Research, Society and Development, 9(7), e341973762-e341973762.

Calello, H. (1986). Gramsci: um modelo para las ciencias sociales (257-277). In. Astorga, O. (Org.). La filosofia de la práxis: de Labriola a Gramsci, Perfiles del Marxismo I. Caracas: Alfadi.

Franco, M. A. S. \& Pimenta, S. G. (2012). Didática: embates contemporâneos. Edições Loyola.

Gamboa, S. S. (2010). Teoria e da prática: uma relação dinâmica e contraditória. In V Colóquio de Epistemologia da Educação Física.

Gil, A. C. (2008). Métodos e técnicas de pesquisa social. 6. Editora Atlas SA.

Gramsci, A. (1989). Concepção dialética da história. (8a ed.), Civilização Brasileira.

Guimarães, J. C. (2014). Competências do professor universitário: a prática como itinerário para a aprendizagem ativa do aluno e para a formação continuada do docente. Revista Pensamento Contemporâneo em Administração, 8(2), 167-185.

Masseto, M. T. (2012). Competência Pedagógica do Professor Universitário. (2a ed.), Summus.

Minayo, M. C. S. (2016). O desafio da pesquisa social. In Minayo, M. C. S., Deslandes, S. F. \& Gomes, R. Pesquisa social: teoria, método e criatividade. pp. 9-28. Vozes.

Moran, J. M. (2013). Caminhos que facilitam a aprendizagem. Novas Tecnologias e Mediação Pedagógica, Papirus, $27-29$.

Nascimento, T. L., Bertini, L. M., \& Sousa Rios, M. A. (2020). A realização de visitas técnicas na formação profissional do Técnico em Química: um estudo de caso. Research, Society and Development, 9(8), e419985651-e419985651. 
Research, Society and Development, v. 10, n. 6, e45610615895, 2021

(CC BY 4.0) | ISSN 2525-3409 | DOI: http://dx.doi.org/10.33448/rsd-v10i6.15895

Neto, J. H. D. (2013). A epistemologia da prática: implicações para a formação de professores da educação básica. Paco Editorial.

Nunes, G. C., Nascimento, M. C. D., \& de Alencar, M. A. C. (2016). Pesquisa científica: conceitos básicos. Id on Line Revista de Psicologia, 10(29), 144-151.

Parecer CNE/CP 9/2001 (2001). Diretrizes Curriculares Nacionais para a Formação de Professores da Educação Básica, em nível superior, curso de licenciatura, de graduação plena. Diário Oficial da União, Brasília, DF: Conselho Nacional de Educação.

Pimenta, S. G. (2009). O estágio na formação de professores: unidade teoria e prática? Editora Cortez.

Pires, M. V. (2019). Reflexão sobre a prática: o que e como reflete uma futura professora de matemática. In International Conference on Innovation, Documentation and Education: INNODOCT/19 (pp. 1107-1115). Universitat Politècnica de València.

Real, G. C. M. (2012). A prática como componente curricular: o que isso significa na prática? Educação e Fronteiras, 2 (5), 48-62.

Saviani, D. (2007). Pedagogia: o espaço da educação na universidade. Cadernos de pesquisa, 37(130), 99-134.

Silva, M. I. L. (2013). Prática educativa, teoria e investigação. Interacções, 9(27).

Silva, K. L., \& Fernandes, J. C. C. (2020). Metodologias Ativas e o Lúdico: Possibilidades de práticas de leitura em salas de aula. Research, Society and Development, 9(7), e122973694-e122973694.

Silva, G. D., Marinho, A. O., Machado, M. K., \& Hoefel, J. L. M. (2019). Aulas de Campo como Instrumentos para difusão da Sustentabilidade. Momentum, 1(17). 